ICNS 2019

\title{
CNS Simulation Tool Development for Increasingly Complex Airspace Operation Evaluation
}

Rafael Apaza, Michael Marsden

NASA Glenn Research Center, Cleveland, Ohio

April 11, 2019 


\section{Presentation Outline}

1. Introduction

2. SMART NAS Testbed Background

3. SMART NAS Testbed Architecture

4. CNS Model Development \& Design

5. Evaluation Results

6. Conclusion 


\section{Introduction}

- NASA Shadow Mode Assessment using Realistic Technologies for the National Airspace System (SMART NAS) initiated Test Bed Development

- Under the Air Traffic Management eXploration (ATM-X) Project, NASA is continuing testbed modernization and expanded development of new simulation tools and capabilities to include operations for new airspace users

- Evaluation of new Air Traffic concepts, technologies and vehicles with new missions seeking entry into the airspace requires the use of simulation capabilities not currently available

- Purpose is to conduct high-fidelity, real-time, human-in-the-loop and automation-in-the-loop simulations

- This presentation describes CNS simulation architecture and software design developmental efforts 


\section{CNS Simulation Background}

- NAS depends on CNS systems to deliver ATM services and these technologies have performance and reliability limitations

- Modern and vintage CNS technologies used today e.g. VOR-DME, GPS

- CNS simulation is required for optimal system architecture design, risk mitigation, operational efficiency, service degradation evaluation, and more.

- CNS modeling provides scalability analysis, efficiency performance, realistic assessment and assist in proof of ATM Concepts

- NASA Glenn Research Center is developing CNS tools to evaluate existing and future ATM concepts that considers existing and new vehicle operations. 


\section{Testbed Architectural Elements}

UAS

UAS Traffic Management $\quad$ Live Virtual Constructive-

(UTM)
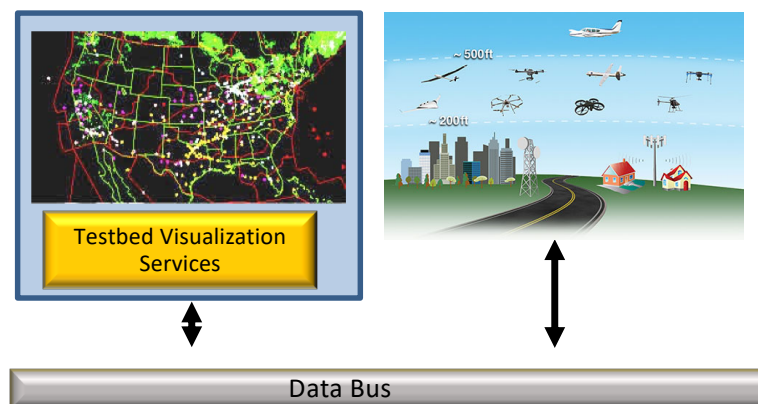

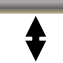

Testbed Distributed Environment (LVC-DE)
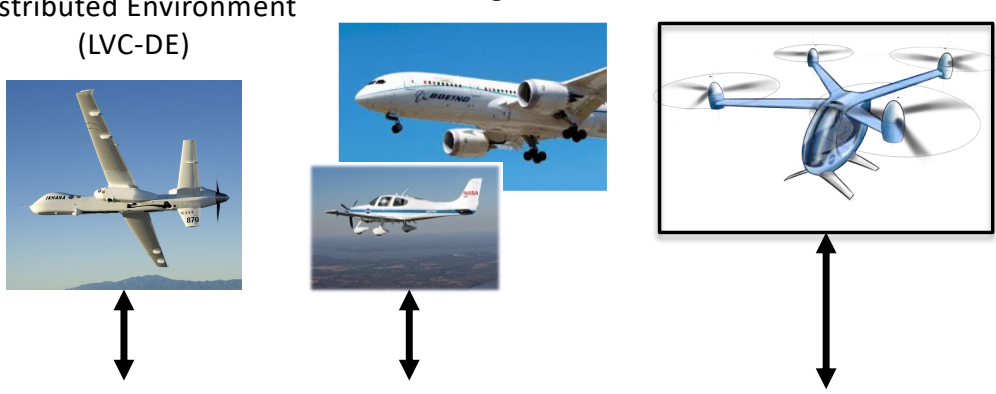
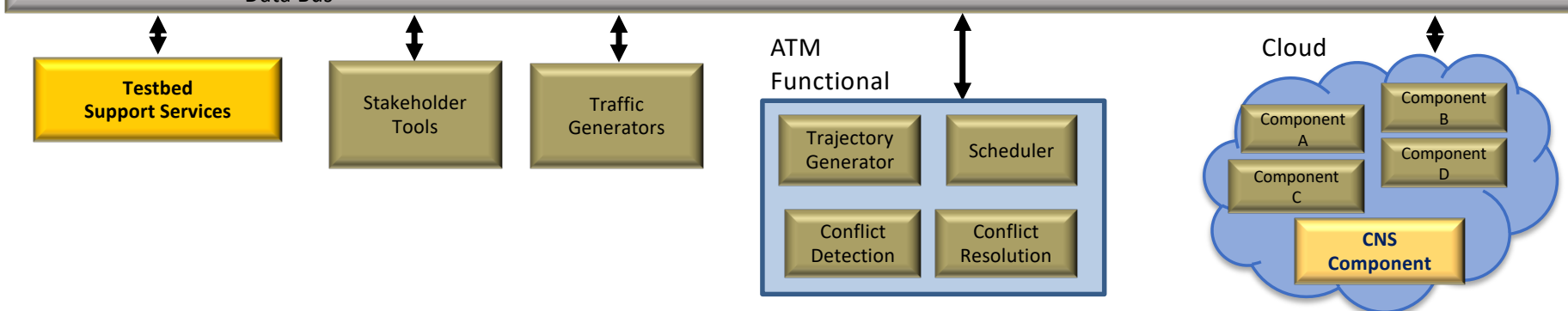


\section{CNS Model Development}

- Navigation Module designed as a submodule of Target Generator

- Navigation Module adds uncertainty to the track

- Provides adjustable parameters for aircraft position variability

- Provides position generation using statistical approximations

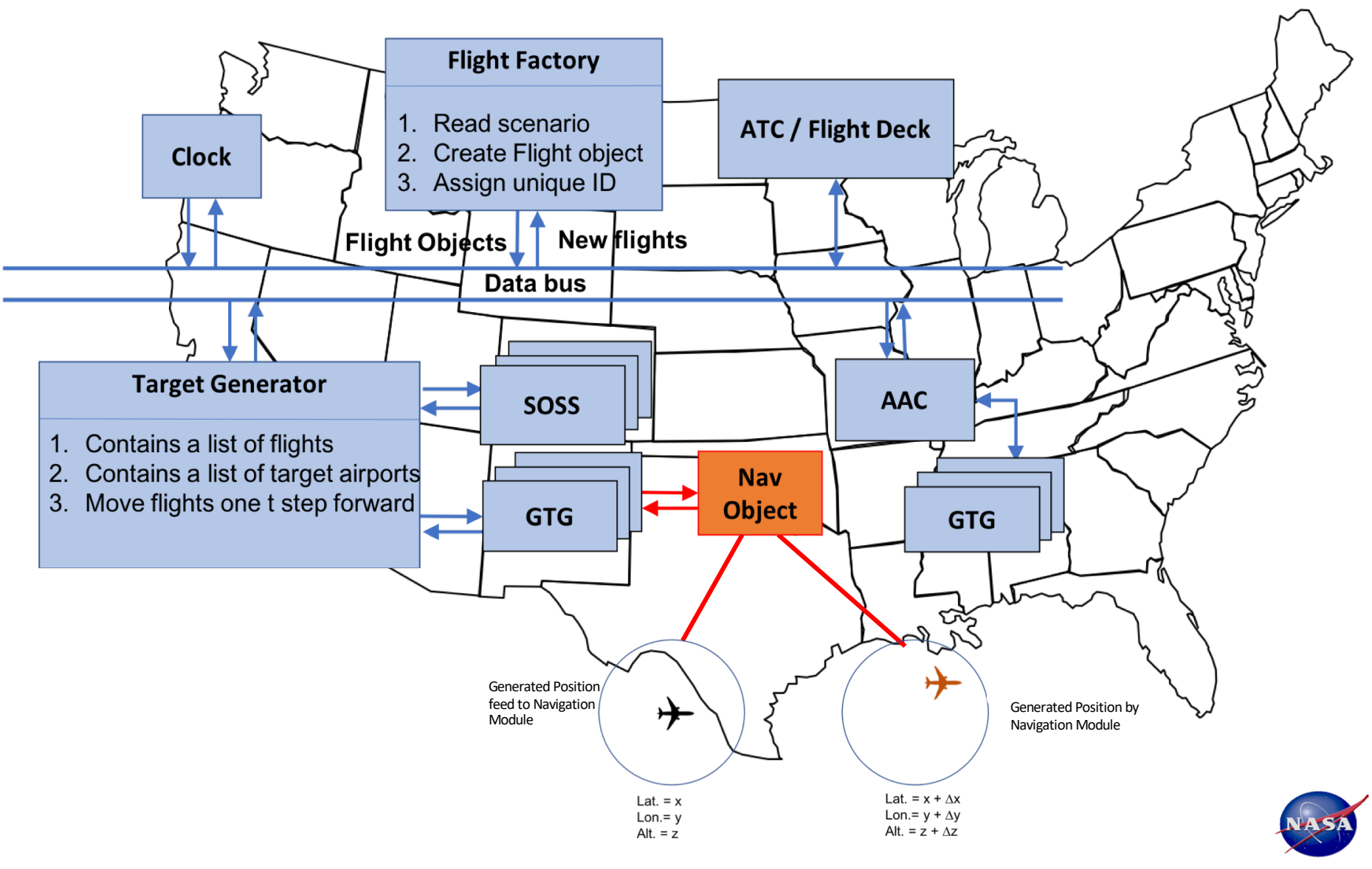




\section{CNS Model Development}

- Development code written in the programming language of Java, using OpenJDK 11.

- Coding standards based on SMART NAS Testbed's (SNTB) Java coding standards.

- Atlassian collaboration products employed such as Jira ${ }^{\circledR}$, Confluence ${ }^{\circledR}$, Bitbucket $^{\circledR}$, and FishEye ${ }^{\circledR}$.

- Agile style approach for software development and project management.

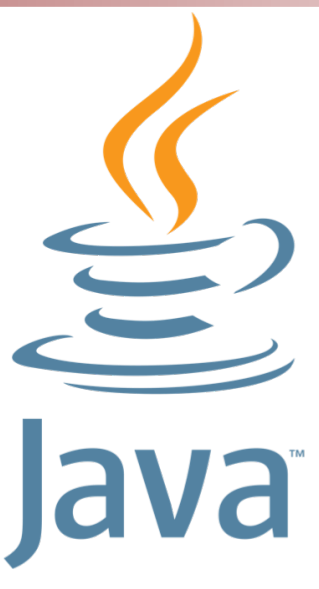

OpenJDK

$\triangle$ ATLASSIAN 


\section{Software Engineering Development}

Agile Approach for Testbed Development

- User stories development \& priority assignment

- User story implementation design

- External Review

- User story task decomposition into tasks - Epic assignment

- Sprint Iteration - coding/testing

- Demonstration to Stakeholders

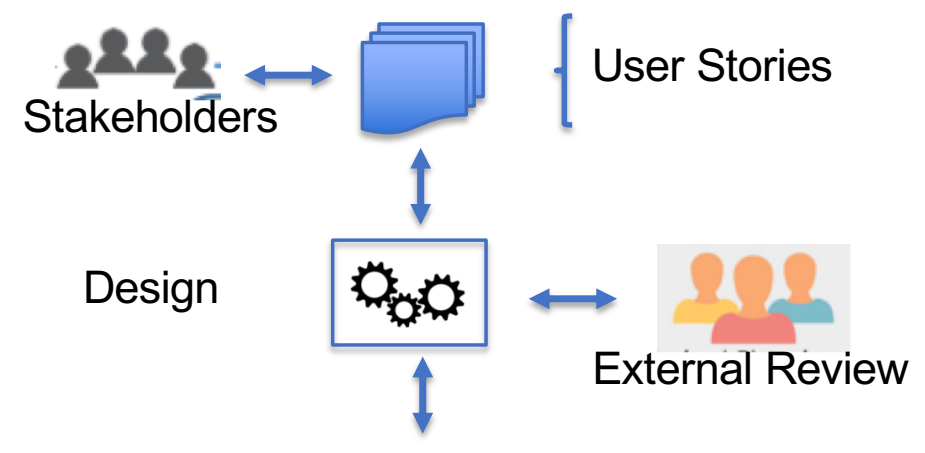

- Release solution into production

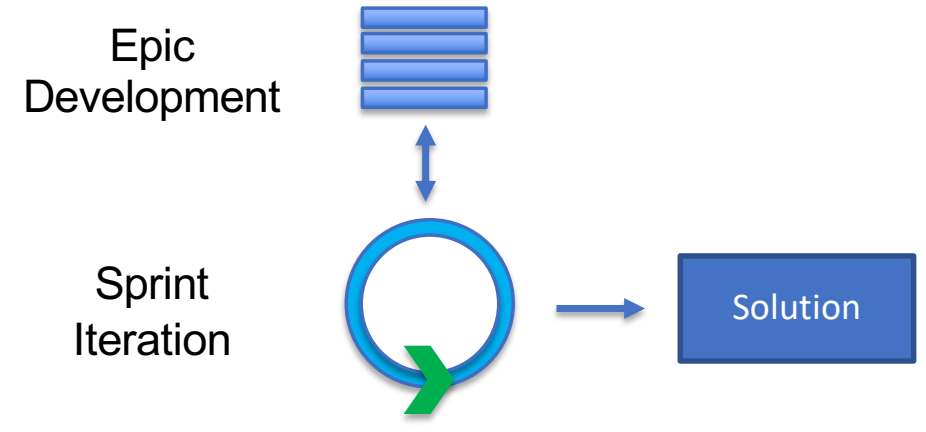




\section{CNS Module Architecture}

High level notional CNS module

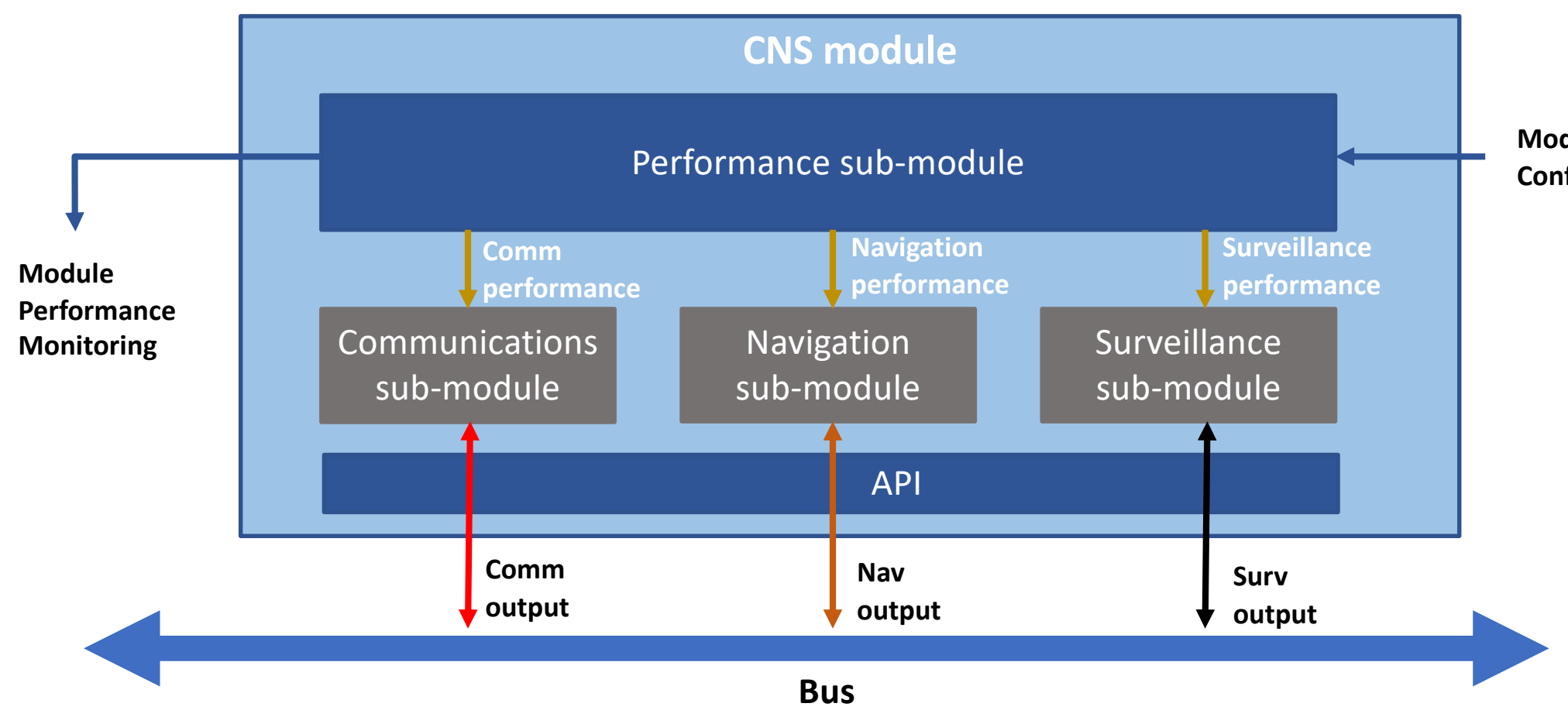

Module Control \&

Configuration 


\section{Navigation Module Architecture}

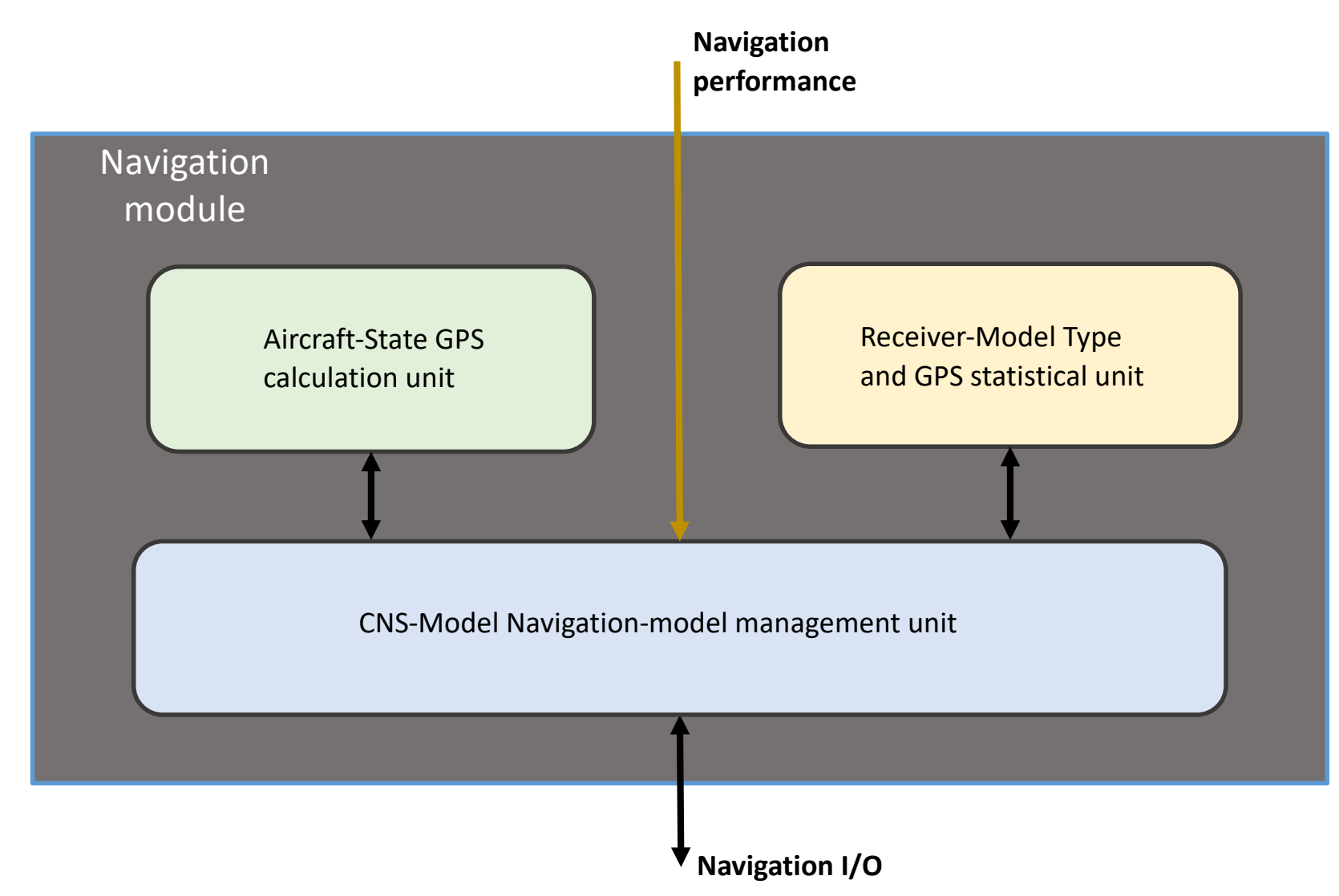

- Management Unit - Controls request and response between the TG and Nav Object, as well as data exchange between internal units.

- GPS Calculation Unit - Holds the current state of the aircraft and calculates the GPS position with applied error based on the input $(x, y, z)$ and GPS errors from the GPS Statistical Unit.

- GPS Statistical Unit - Holds the values for inherent GPS errors and a ReceiverType. 


\section{Model Design Error Considerations}

- Ephemeris - Errors in the transmitted location of the satellite.

- Clock - Residual errors from clock drift and noise in the transmitted clock.

- Ionospheric - Errors caused by the signal transmission through the lonosphere.

- Tropospheric - Errors caused by the signal transmission through the Troposphere.

- Thermal noise - Errors caused by the receiver's thermal noise.

- Multipath - Errors caused by reflected signals entering the receiver antenna.

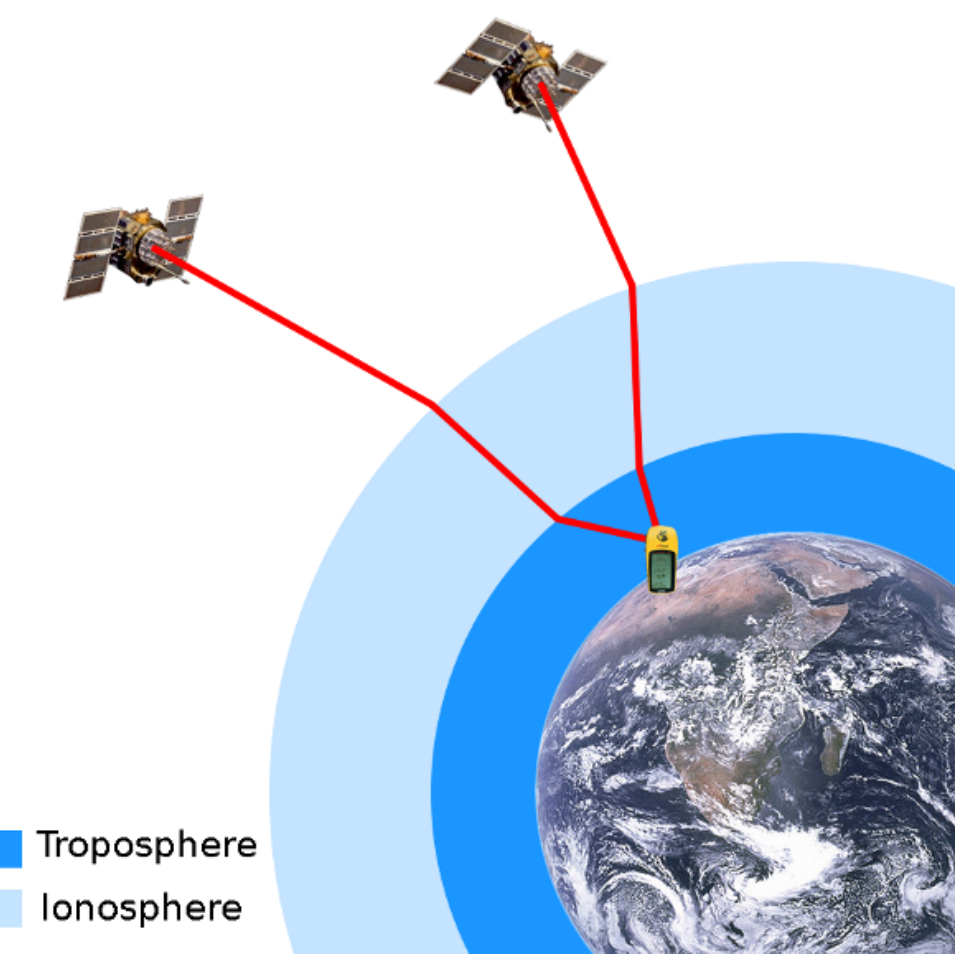


National Aeronautics and Space Administration

\section{Module Design - Position Determination}

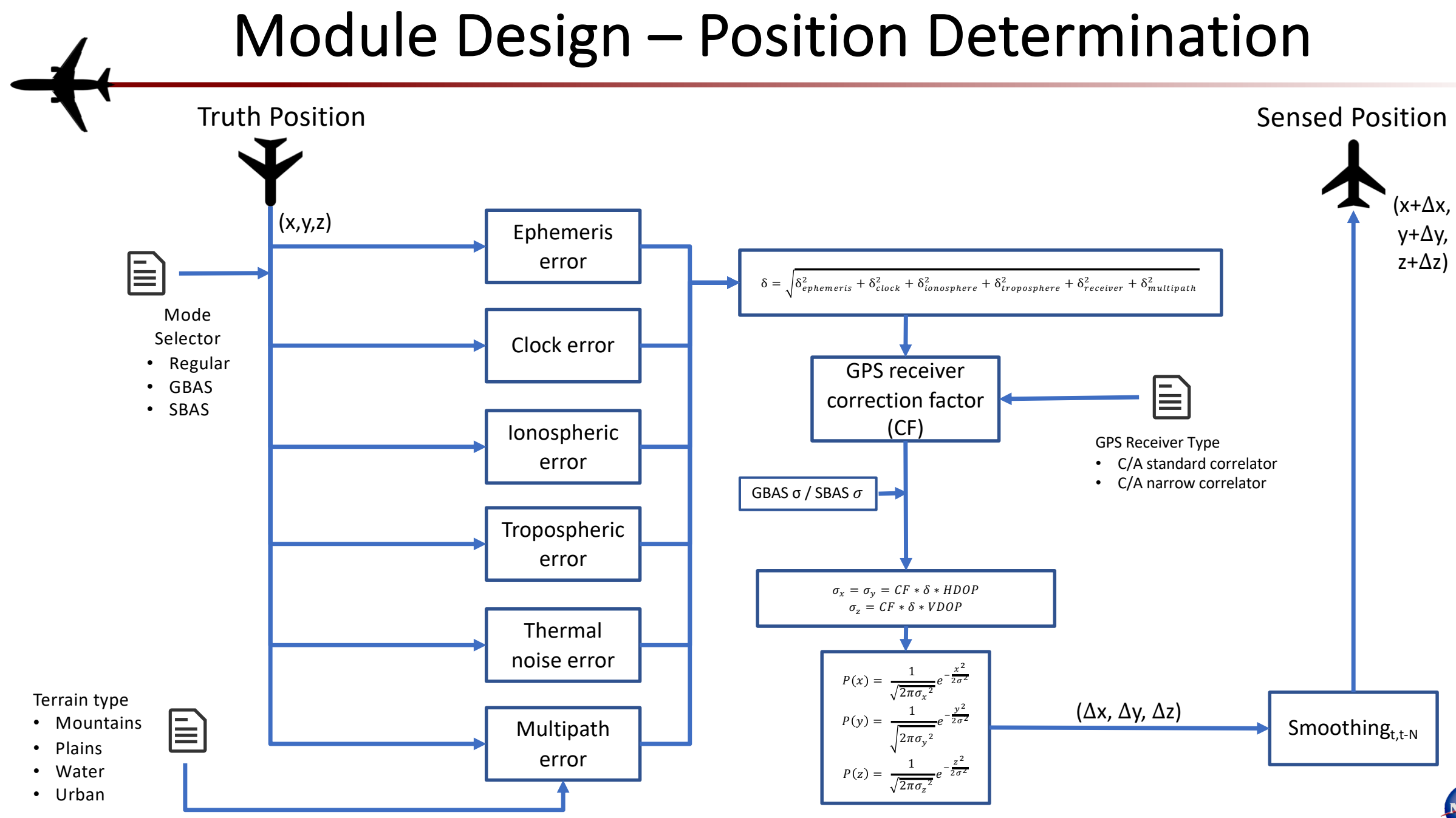


National Aeronautics and Space Administration

\section{Navigation Module Evaluation}
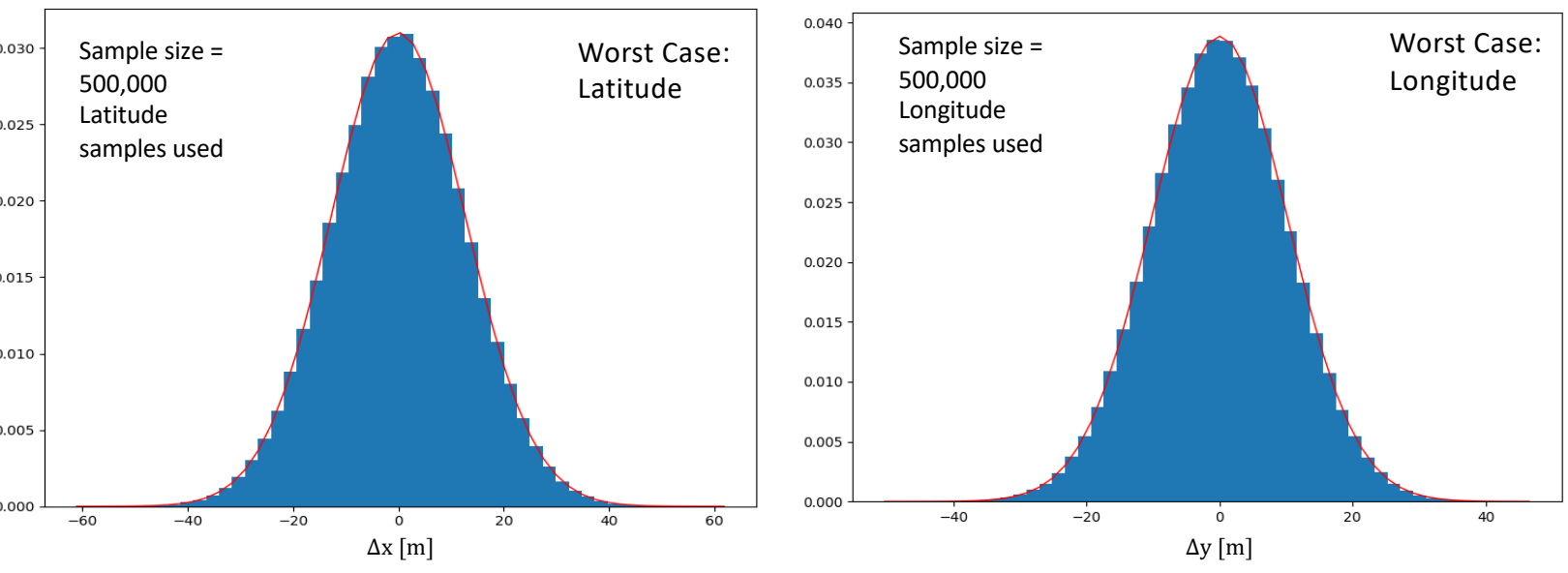

Max Latitude Error:

Max Longitude Error: $\quad 87.0558$

Max Altitude Error:

133.6660

meters

Min Latitude Error: $\quad-71.3894 \quad$ meters

Min Longitude Error: $\quad-67.0877$ meters

Min Altitude Error: $\quad-108.8807 \quad$ meters

Mean Latitude Error: $\quad-0.0172 \quad$ meters

Mean Longitude Error: 0.0028 meters

Mean Altitude Error: 0.0066 meters

StdDev Latitude Error: 12.8611 meters

StdDev Longitude Error: 10.2665 meters

StdDev Altitude Error: $13.6646 \quad$ meters
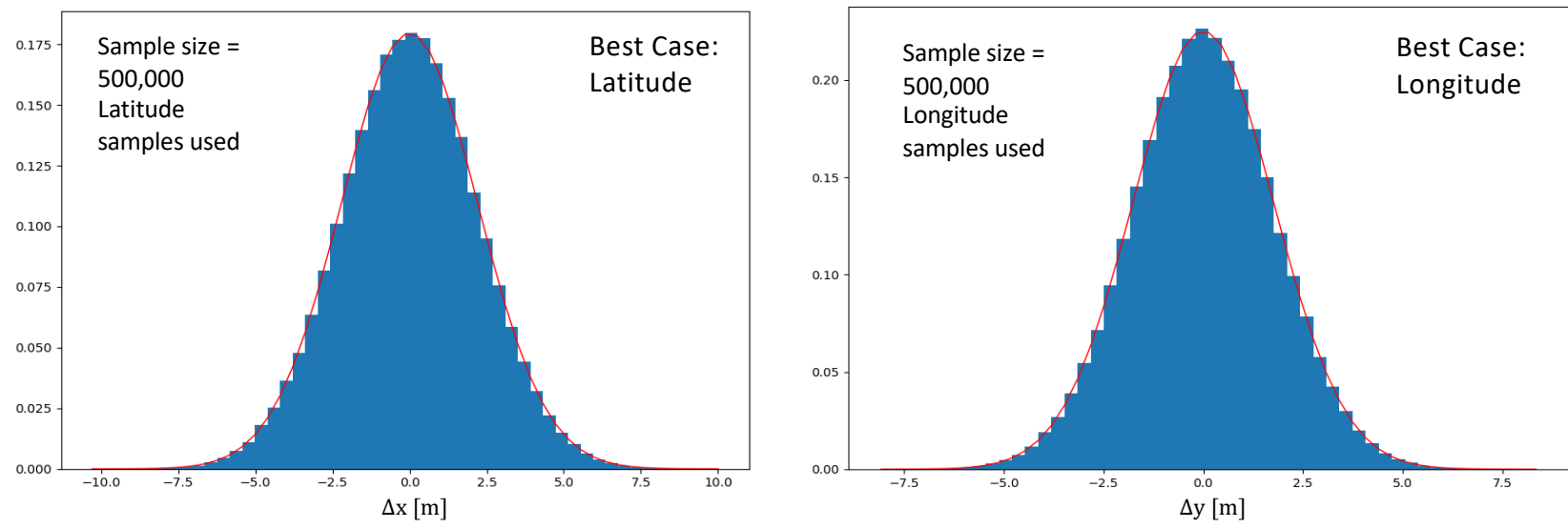

Max Latitude Error: $\quad 11.7612 \quad$ meters

Max Longitude Error: $\quad 9.2523 \quad$ meters

Max Altitude Error: $18.1641 \quad$ meters

Min Latitude Error: $\quad-11.2876 \quad$ meters

Min Longitude Error: $\quad-9.7336 \quad$ meters

Min Altitude Error: $\quad-16.8812 \quad$ meters

Mean Latitude Error: $\quad-0.0019 \quad$ meters

Mean Longitude Error: $-0.0003 \quad$ meters

Mean Altitude Error: $\quad 0.0037 \quad$ meters

StdDev Latitude Error: $2.2216 \quad$ meters

StdDev Longitude Error: 1.7719 meters

StdDev Altitude Error: $\quad 2.3669$

meters 


\section{Navigation Module Evaluation}

KML overview with Blue $=$ Truth_Position, Red $=$ Sensed_Position

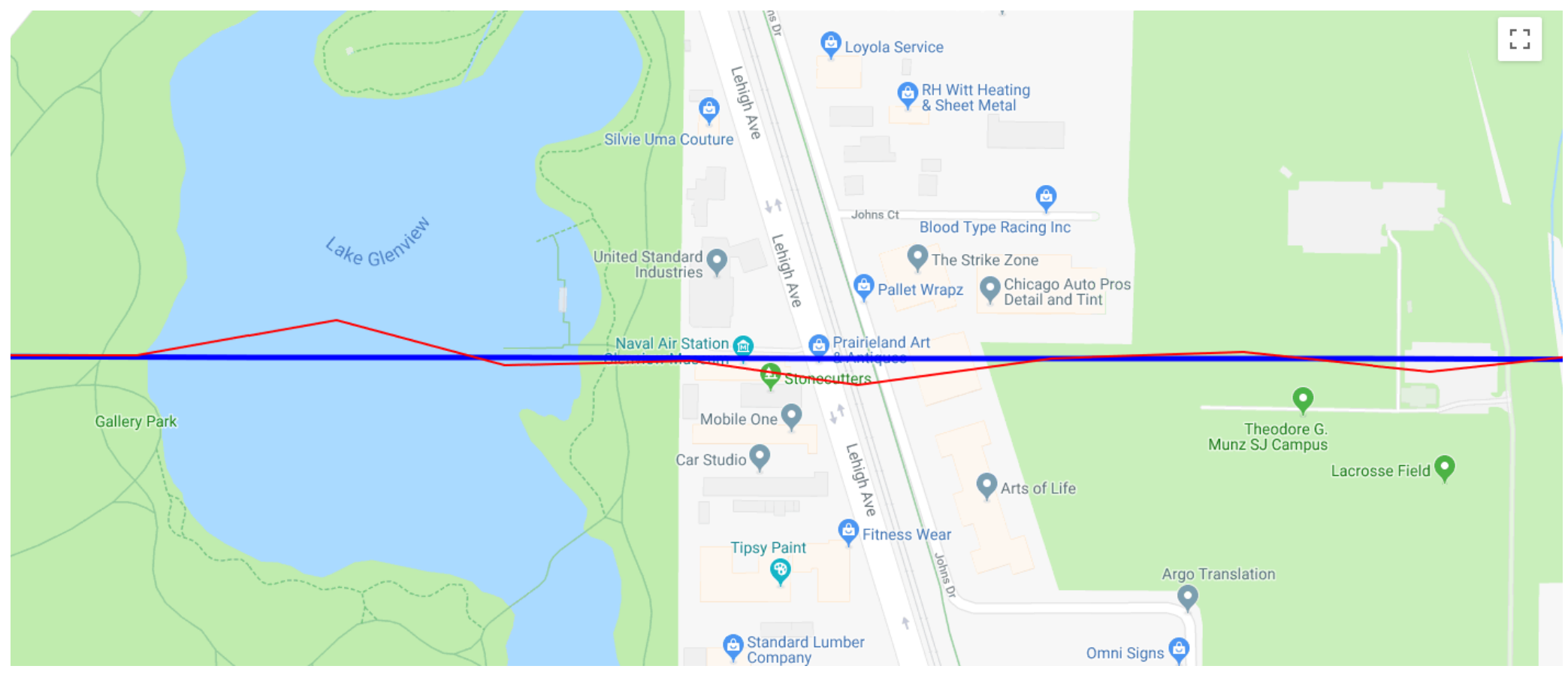




\section{Next Phases}

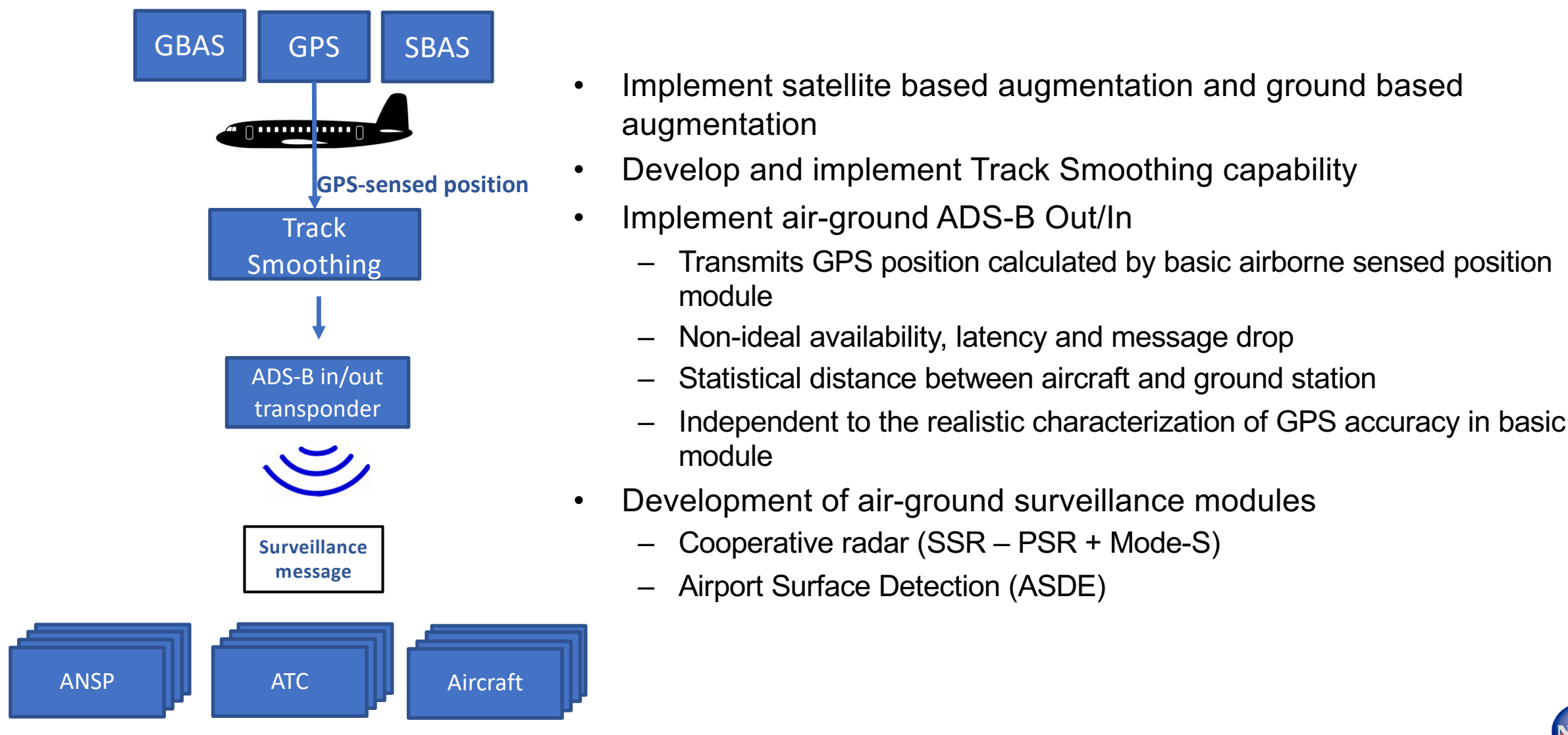




\section{Conclusions}

- A new suit of tools are required to evaluate future concepts of operations and meet the fast evolving demand for new vehicle entries and their operations in the NAS

- Under the SMART NAS project, NASA started the effort to develop state of the art capabilities to meet new challenges and demands for expediting complex concept evaluation.

- A simulation environment that evaluates complex operations in a realistic environment needs to be user friendly, interoperable with existing and new tools, modular, have adequate fidelity, security, scalability and cost effective.

- NASA Glenn Research Center is developing new and improved CNS simulation tools for a realistic evaluation of ATM concepts for existing and new vehicle operations. 